\title{
Magnesium pemoline: Effect on food reinforced discrimination performance in rats'
}

KARL W. SCHOLZ, ${ }^{2}$ Villanova University, DUDLEY F. PEELER, Laboratory of Experimental Behavior, University of Mississippi Medical Center, Jackson, Miss., and O. BYRON WARD, JR., Villanova University, Villanova, $P a$.

Rats injected with magnesium pemoline reached acquisition criterion in a visual discrimination task with significantly fewer reinforced trials than control Ss. However, on retention tests given four and six weeks later, control Ss performed significantly better than drug Ss. The results suggest that magnesium pemoline enhances stimulus responsiveness and motor activity rather than directly affecting central learning processes.

The enhancement of performance by magnesium pemoline (Pemoline Magnesium Hydroxide, PMH) has been interpreted in several ways. Plotnikoff (1966) reported that the drug enhanced learning and retention of an avoidance response. However, other similar studies have concluded that only performance is affected due to enhancement of activity (Gurowitz, Lubar, Ain, \& Gross, 1967) or stimulus responsiveness (Beach \& Kimble, 1967; Filby, Szara, \& Salzman, 1967). The present study was conducted in an attempt to reconcile these differences using ratio of correct to incorrect responses in a visual discrimination task, a dependent variable not easily contaminated by activity variation.

\section{METHOD}

The Ss were 26 male Sprague-Dawley rats, 100 days old at the start of the experiment.

Discrimination apparatus consisted of a standard operant conditioning box. A stimulus light was placed over each of two bars located in one end of the box. A food cup was centered between the bars. Food delivery ( $45 \mathrm{mg}$ Noyes pellets) and illumination of each light were controlled by programming apparatus housed in an adjacent room.

A limited feeding regime ( $20 \mathrm{~g}$ Purina Lab Chow per day) was initiated seven days prior to discrimination training and maintained throughout acquisition. Ss were initially shaped to bar press to a criterion of 30 responses in $15 \mathrm{~min}$. On the day following the completion of shaping for each $S$, injections and discrimination training were initiated. Thirty minutes prior to each acquisition session, half the Ss were injected IP with PMH (20 $\mathrm{mg} / \mathrm{kg}$ in $0.3 \%$ tragacanth) and half with tragacanth. During all acquisition and retention sessions, a correct response consisted of pressing the bar under the illuminated light. When this occurred, the light was extinguished, a food pellet was delivered, and $1 \mathrm{sec}$ later one of the two lights came on at random. When the bar under the nonilluminated light was pressed, no food was given, an error was counted, and the other light remained illuminated. Ss were given daily $15 \mathrm{~min}$ sessions until the ratio of correct to incorrect response $(\mathrm{C} / \mathrm{I}$ ratio) reached $5 / 1$ for three consecutive days.

Two retention tests were given 30 and 45 days after each $S$ reached criterion. No injections were given during the first test. For the second test, each $\mathrm{S}$ was injected with PMH or tragacanth $30 \mathrm{~min}$ before the session as it had been during acquisition training.

Prior to discrimination training, 10 of the $26 \mathrm{Ss}$ were used to assess the effect of PMH on food intake. Thirty minutes before the daily $20 \mathrm{~g}$ food ration was placed into the home cage, half the Ss were injected with PMH and half with tragacanth. This procedure was initiated when the Ss had been on the limited feeding schedule for one week and was continued for 14 days. Although PMH has been reported to reduce ad libitum food consumption (Pizzi, See, \& Kohn, 1968), there was no effect of the drug on daily $1 \mathrm{~h}$ food intake over the 14day period.

\section{RESULTS}

The Ss required from 7 to 12 sessions to learn the discrimination task to criterion. Mean number of reinforcements received during acquisition was significantly less for the drug group than for the placebo group $(p<.05)$. On the last three acquisition days for each animal, control and drug Ss did not differ significantly in $\mathrm{C} / \mathrm{I}$ ratio (14.96 vs 13.36).

Mean $\mathrm{C} / \mathrm{I}$ ratio and mean total responses per session were analyzed for the first seven acquisition sessions and two retention tests using analyses of variance designs. Performance scores are illustrated in Fig. 1. Drug and placebo groups were found to differ significantly with respect to $C / I$ ratio during both acquisition and retention $(p<.05)$. During acquisition, drug injected animals performed at a higher $\mathrm{C} / \mathrm{I}$ ratio than controls after the first few sessions, but on both retention tests they performed significantly below the controls. Both experimental and control Ss performed significantly better on the injection retention test than on the noninjection retention test $(p<.05)$. Total responses for the two groups were found to be not significantly different during acquisition or retention, but during acquisition the Drug Condition by Session interaction was significant $(p<.01$; see Fig. 1). As a consequence of increased responding, drug Ss received more reinforcement during the initial discrimination sessions than control Ss. However, by the seventh session when cumulative number of correct as well as cumulative total responses were equalized for the two groups, the $\mathrm{C} / \mathrm{I}$ ratio indicated superior performance for the drug $\mathrm{Ss}$.

\section{DISCUSSION}

PMH enabled drug Ss to attain the acquisition criterion (C/I) performance level with significantly fewer reinforced

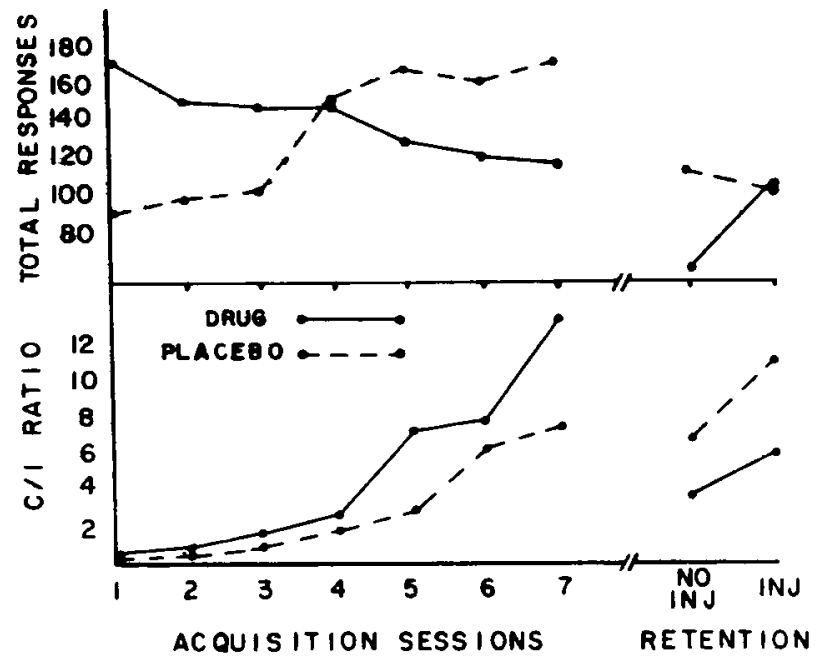

Fig. 1. Mean C/I ratio (bottom) and mean total responses (top) per session for PMH- vs tragacanth-injected Ss during acquisition and retention of a visual discrimination task. Since some Ss reached acquisition criterion by the seventh session, only the data for the first seven acquisition sessions which included all $\mathrm{Ss}$ is shown. 
responses than controls. However, the inferior $\mathrm{C} / \mathrm{I}$ performance on retention tests by drug Ss shows that they had not actually learned the discrimination task as well as controls. Thus, the effect of PMH would appear to be on a performance variable and unrelated to central associative processes. Other investigators have shown that PMH may enhance acquisition performance by increasing responsiveness to external stimuli (Beach \& Kimble, 1967) or attentiveness (Talland, 1966), rather than by facilitating central learning processes. Considering the requirements of the behavioral task, this conclusion seems to provide a reasonable interpretation of the present data.

During the injection retention test, a single administration of PMH did not result in a level of performance comparable to acquisition for the drug Ss. Further, the single dose of PMH did not enhance retention performance any more than a tragacanth injection facilitated the retention performance of control Ss. This suggests that the effects of PMH injection during acquisition may have been cumulative.

Two hypotheses have been used to account for the interaction in total responses during acquisition. It is suggested that total responses for the drug group is higher than for controls on the first session because of PMH induced increase in activity level. On subsequent sessions, the drug group emitted progressively fewer responses because as they acquired a greater degree of proficiency on the discrimination task, they received the same quantity of food with fewer total responses than the controls. For control Ss, the C/I ratio was significantly lower than for the drug group, which indicates that controls emitted more responses per reinforcement. Controls were thus responding on a higher order partial reinforcement schedule which would generate a higher response rate.

\section{REFERENCES}

BEACH, G., \& KIMBLE, D. P. Activity and responsivity in rats after magnesium pemoline injections. Science, 1967, 155, 698-701.

FILBY, Y., SZARA, S., \& SALZMAN, B. Mognesium pemoline: Effect on acquisition and retention of discriminated avoidance behavior. Psychonomic Science, 1967, 9, 131-132.

GUROWITZ, E. M., LUBAR, J. F., AIN, B. R., GROSS, D. A. Disruption of passive avoidance learning by magnesium pemoline. Psychonomic Science, 1967, 8, 19-20.

PIZZI, W. J., SEE, C. S., II, \& KOHN, H. M. Effects of magnesium pemoline on food and water intake in rats. Psychonomic Science, $1968,11,81-82$.

PLOTNIKOFF, N. Magnesium pemoline: Enhancement of learning and memory of a conditioned avoidance response. Science, 1966, 151, 703-704.

TALLAND, G. A. Improvement of sustained attention with Cylert. Psychonomic Science, 1966, 6, 493-494. NOTES

1. We thank Dr. H. G. Schoepke, Abbott Laboratories, for providing the magnesium pemoline. This investigation was partially supported by Public Health Service Training Grant No. NB05411 from the Institute of Neurological Diseases and Blindness.

2. Present address: Department of Psychology, Indiana University, Bloomington, Indiana. 